\title{
ESTADO DA ARTE SOBRE A CRECHE NAS POLÍTICAS EDUCACIONAIS (2000-
}

2005)

\author{
Liliane Pacheco Goncalves'; Faní Quitéria Nascimento Rehem²; \\ 1. Bolsista PROBIC/UEFS, Graduanda em Licenciatura em Pedagogia, Universidade Estadual de Feira de Santana, e- \\ mail:liliane96@gmail.com \\ 2. Orientadora, Departamento de Educação, Universidade Estadual de Feira de Santana, e-mail: fanirehem@gmail.com
}

PALAVRAS-CHAVE: Creche; Política educacional; Educação infantil.

\section{INTRODUÇÃO}

Este texto refere-se ao estudo intitulado "Estado da arte sobre a creche nas políticas educacionais (2000-2005)" aprovado pelo PROBIC-UEFS, desenvolvido no Centro de Documentação em Educação - CEDE - da Universidade Estadual de Feira de Santana UEFS - em que emerge como objetivo de estudo: Identificar e analisar as principais características das teses e dissertações produzidas no período de 2000 a 2005 sobre a creche nas políticas educacionais. Tal pesquisa se caracteriza por um estudo de cunho qualitativo, uma vez que essa abordagem possibilita uma perspectiva mais exploratória do objeto de pesquisa e tem como questões norteadoras: Quais as principais características das teses e dissertações produzidas no período de 2000 a 2005 sobre a creche nas políticas educacionais? Quais as principais concepções que fundamentam as produções científicas sobre a Creche? E finalmente, como a Creche se constitui enquanto política educacional?

\section{MATERIAL E MÉTODOS OU METODOLOGIA (ou equivalente)}

Esta pesquisa se constitui como um "Estado da arte", também denominado "Estado de conhecimento" que foi produzido a partir da análise das teses e dissertações sobre políticas educacionais no Brasil. A realização de estudos nesta perspectiva promove um balanço da pesquisa de uma determinada área. Para Romanowski (2006, p. 39) "A realização destes balanços possibilita contribuir com a organização e análise na definição de um campo, uma área, além de indicar possíveis contribuições da pesquisa para com as rupturas sociais". Assim, compreendemos a relevância dessa abordagem, para constituição de um campo de conhecimento.

É muito comum que o levantamento bibliográfico das produções em determinada área de conhecimento seja feita a partir dos resumos, conforme indica Ferreira (2002). No entanto Medig (1999) alerta que os resumos por serem muito sucintos e, em muitos casos, mal elaborados, não são suficientes para a divulgação dos resultados. Para o autor "É preciso ter o texto original da tese ou dissertação disponível para leitura e consulta" (MEDIG, 1999, p.28, apud FERREIRA, 2002, p.266). Portanto, ressaltamos, com isso, a necessidade de aprofundar o estudo realizando a leitura completa do texto final das produções sobre a creche nas políticas educacionais, buscando identificar as principais características, avanços e lacunas da produção acadêmica.

Como corpus de análise foram utilizadas as 1.283 teses e dissertações que foram coletadas, em pesquisa anterior, no banco de teses da CAPES. Este catálogo decorreu do projeto de pesquisa intitulado "Questões epistemológicas e metodológicas da produção acadêmica em políticas educacionais no Brasil”, que objetiva analisar as características epistemológicas e metodológicas de teses e dissertações sobre políticas educacionais produzidas no período de 2000 a 2010 nos programas de pós-graduação em educação, que tiveram nota igual ou superior a 05 na avaliação da Capes no triênio que se encerrou em 2010. 


\section{RESULTADOS E/OU DISCUSSÃO (ou Análise e discussão dos resultados)}

Apesar do reconhecimento legal dessa etapa da educação básica, a Creche ainda figura como um desafio na garantia da educação infantil como direito universal, haja vista a informação da Pesquisa Nacional por Amostra de Domicílios (Pnad) 2015, do Instituto Brasileiro de Geografia e Estatística (IBGE) (BRASIL, 2017) de que apenas $25 \%$ das crianças menores de 4 anos frequentam a educação infantil. Ainda que muito presente nos discursos políticos, a educação da criança até cinco anos de idade, pouco se efetiva na implementação das políticas públicas. Esse cenário de pouco acesso das crianças a este direito, evidencia a pouca importância política que é dada à creche, o que reflete em nossa interpretação, na produção acadêmica na área, "tendo a faixa etária zero a três anos - ou seja, crianças frequentadoras de Creche - o menor número de publicações [...], indicando que há mais análises da prática do que da política, com foco mais na atividade do que no contexto" (REHEM, 2013, p. 27-28).

A pesquisa se inicia no banco de dados organizado pelo Centro de Documentação em Educação - CEDE com 1.283 teses e dissertações coletadas no banco de teses da CAPES. Neste banco selecionamos as pesquisas produzidas no período de 2000 a 2005 que tratam sobre a creche nas políticas educacionais, para tanto utilizamos como forma de catalogação os descritores: creche; zero a três anos. A escolha por esses termos se deu pela busca de teses e dissertações que analisassem especificamente a creche, que se constitui como parte da Educação Infantil, atendendo crianças de zero a três anos de idade.

Após essa primeira identificação, através da leitura dos resumos dos mesmos identificamos que apenas três tratavam especificamente da creche. A partir da seleção dessas dissertações, elaboramos um novo banco de dados, especifico para essa pesquisa, organizando-o por ano de defesa e eixo. As dissertações analisadas pertencem ao eixo ${ }^{1}$ 01(um) nomeado como "Organização da educação, planejamento da educação, administração da educação, gestão da educação" e eixo 04 (quatro), denominado "Reformas educacionais, neoliberalismo na educação, terceiro setor e organizações sociais na educação, Estado e reformas educacionais, análise e avaliação de políticas educacionais".

Verificou-se ainda que as três dissertações selecionadas para leitura, por fim, foram defendidas no ano de 2005 e analisam sobre a Creche nas políticas educacionais em algum estado ou cidade específica, das regiões sul e sudeste, em vista disso percebe-se que não há uma leitura em caráter de escala nacional das políticas educacionais voltadas para a Creche ou acerca de seus impactos nas demais regiões do país. É possível que esse fato seja em virtude das produções terem sido realizadas apenas em universidades de São Paulo e Porto Alegre, sendo estas: UNICAMP e UFRGS.

Destaca-se que os resumos de todas as produções analisadas se encontram parcialmente completo ${ }^{2}$, visto que não apresentam com clareza alguns dos critérios que

\footnotetext{
1 A pesquisa Produção Acadêmica em Políticas Educacionais no Brasil - 2000-2010, banco de dados investigado, se constitui por nove eixos. São eles: Eixo 1 - Organização da educação, planejamento da educação, administração da educação, gestão da educação; Eixo 2 - Avaliação em larga escala e avaliação institucional; Eixo 3 - Qualidade da educação, qualidade de ensino; Eixo 4 - Reformas educacionais, neoliberalismo na educação, terceiro setor e organizações sociais na educação, Estado e reformas educacionais, análise e avaliação de políticas educacionais; Eixo 5 - Políticas de Formação de professor, carreira docente; Eixo 6 - Financiamento da educação, controle social do financiamento da educação; Eixo 7 - Abordagens teórico-metodológicas em pesquisas sobre políticas educacionais; Eixo 8 - Análise e avaliação de Programas e projetos no campo educacional; Eixo 9 - Políticas inclusivas.

2 Estabelecemos enquanto critérios de classificação dos resumos: Completo, aqueles que evidenciam com clareza problemática de estudo, objetivo, estratégia metodológica, base teórica, resultados alcançados; Parcialmente completo aqueles que evidenciam com clareza no mínimo três critérios relacionados ao resumo completo; Insuficiente aqueles que não evidenciam com clareza a problemática de estudo, objetivo, estratégia metodológica, base teórica, resultados alcançados, o que torna a compreensão do propósito da pesquisa difícil.
} 
indicam a qualidade dos resumos, como a problemática de estudo, objetivo, estratégia metodológica, base teórica e resultados alcançados. Este cenário evidencia as limitações de análises em estado da arte realizadas apenas a partir da leitura de resumos.

Ao realizar a leitura completa das dissertações na busca por identificar as principais características nas discussões sobre creche nas políticas educacionais, percebemos que é comum a todas elas, trazer o histórico de surgimento da Educação Infantil, destacando as contribuições teóricas de Moyses Khulmann Jr., Sonia Kramer, Maria Evelyna Pompeu do Nascimento e Zilma de Moraes Ramos de Oliveira, estudiosos referenciais a essa temática. Destaca-se o fato de que uma das dissertações praticamente não traz referencial teórico da discussão sobre Creche ou Educação Infantil, utilizando como suporte apenas os documentos legais, como a Constituição Federal de 1988, o Estatuto da Criança e do Adolescente de 1990 e a Lei de Diretrizes e Bases da Educação Nacional - LDB 9394/1996.

Outro aspecto interessante, é que apesar da história da educação infantil estar relacionada ao surgimento do sentimento de infância, apenas uma autora se dedica a trazer essa discussão em sua pesquisa. Assim sendo, essa autora utiliza como suporte teórico Gélis (1991) e Ariès (1981). Diferentemente, do debate sobre as mobilizações de mulheres, mães e feministas nas décadas de 1970 e 1980 no Brasil, que pressionaram o Estado na criação das creches, que é abordado em todos os trabalhos que fizeram parte deste estudo. Há uma unanimidade na utilização das contribuições teóricas de Fúlvia Rosemberg.

\section{CONSIDERAÇÕES FINAIS}

$\mathrm{Na}$ busca por dar a devida visibilidade à temática, o intuito dessa pesquisa consiste em revelar o debate sobre as Creches nas políticas educacionais, analisando a produção encontrada no banco de dados constituído a partir das teses e dissertações produzidas no período de 2000 a 2005 nos programas de pós-graduação em educação e identificando as principais características nas discussões.

Neste universo de teses e dissertações analisados nesta pesquisa, que têm a Creche como foco no debate das políticas educacionais, revelou um aumento significativo da produção dessa área no último ano do recorte de tempo pesquisado (2005), ainda assim os resultados obtidos indiquem a pouca produção com foco nas políticas educacionais para a Creche, revelando a fragilidade teórica do campo.

Para além disso, verificou se que das 1.283 produções acadêmicas, somente dissertações foram analisadas, constituindo um número de três pesquisas investigadas ao todo, todas realizadas nas regiões sul e sudeste do Brasil. É importante levar em consideração que o banco de dados dispõe de uma quantidade maior de dissertações de mestrado do que teses de doutorado.

Em relação à discussão, o referencial teórico, bem como os instrumentos e estratégias de coletas de dados adotados pelas produções acadêmicas, se assemelham em todas as produções analisadas revelando ser uma característica das pesquisas sobre a Creche nas políticas educacionais, quais sejam: questionários escritos, entrevistas e análise documental. As produções acadêmicas analisadas se atém principalmente ao contexto político, com a predominância da discussão sobre Creche, no surgimento desta no Brasil, o caráter que essa assumia e como esta passou a ser considerada política social. No entanto, alguns autores clássicos na discussão sobre Educação Infantil nas políticas educacionais não aparecem nas dissertações de mestrado analisadas.

Por fim, consideramos, ainda, que esta pesquisa se somará ao debate sobre políticas educacionais dando o destaque necessário à creche como etapa fundamental da educação infantil ao organizar um banco de dados sobre a política educacional sobre creche, visando servir de referência para os estudos que envolvem a temática em educação infantil. 


\section{REFERÊNCIAS}

ARCE, A. As pesquisas da área de educação infantil e a história da educação: reconstruindo a história do atendimento às crianças pequenas no Brasil, 2004. Disponível em: http://www.anped.org.br/reunioes/27/gt02/t021.pdf). Acessado em: 08 de mar de 2017

BRASIL, IBGE. Pesquisa Nacional por Amostra de Domicílios, 2015. Aspectos dos cuidados das crianças de menos de 4 anos de idade. 2017. Disponível em: https://biblioteca.ibge.gov.br/visualizacao/livros/liv100137.pdf. Último acesso em 01 abri 2018.

FERREIRA, Norma Sandra de Almeida. As pesquisas denominadas "estado da arte".Educ. Soc. 2002, vol.23, n.79. Disponível em: < http://www.scielo.br/pdf/es/v23n79/10857.pdf> Acessado em: 15 de mar de 2017. doi.org/10.1590/S0101-73302002000300013.

KRAMER, Sonia.As crianças de 0 a 6 anos nas políticas educacionais no Brasil: educação infantil e/é fundamental. Educ. Soc. 2006, vol.27, n.96. Disponível em: <http://www.scielo.br/pdf/es/v27n96/a09v2796.pdf> Acessado em: 15 de mar de 2017.doi.org/10.1590/S0101-73302006000300009.

MORGAN, Dimas Anaximandro da Rocha; SILVA, Joelma Gomes da; KNACKFUSS, Maria Irany e MEDEIROS, Humberto Jefferson de.As políticas públicas no contexto da educação infantil brasileira. Constr. psicopedag. 2014, vol.22, n.23, pp. 51-58. ISSN 14156954. Disponível em: <http://pepsic.bvsalud.org/scielo.php?script=sci_arttext\&pid=S141569542014000100004> Acessado em: 15 de mar de 2017.

REHEM, F. Q. N. “Coisa de pobre": a política de educação infantil em Feira de Santana (2001-2008). Tese (Doutorado em Política Social), Departamento de Serviço Social, Universidade de Brasília, Brasília, 2013.

ROMANOWSKI, J. P.; ENS, R. T. As pesquisas denominadas do tipo "estado da arte" em educação. Diálogo Educacional, v. 6, n. 19, p. 37-50, set./dez., 2006

STRENZEL, G. R. A produção científica sobre educação infantil no Brasil nos programas de pós-graduação em educação.In: 23A REUNIÃO ANUAL DA ANPEd, 2000, Caxambu. Anais... Rio de Janeiro: ANPEd, 2000. 